\title{
A Rare Hepatic Arterial Variation Established in Preoperative MDCT Angiography
}

\author{
Ali Onder Atca, Ebru Yılmaz*, Berrin Erok, Ayhan Yılmaz, Erhun Eyupoglu and Turgut Ipek
}

Department of Physical Medicine and Rehabilitation, GOP Taksim Education and Training Hospital, Turkey

\begin{abstract}
Preoperative evaluation and exact description of origins and courses of hepatic vasculature is essential to avoid iatrogenic complications and to have effective results in surgical and radiologic procedures of hepatobiliary pancreatic region. Therefore, preoperative visceral angiography is critical. Digital substraction angiography is gold standart for the evaluation of vascular structures but its invasive nature limits its use. In recent years with the introduction of Multidetector CT (MDCT) Angiography, the use of conventional angiography has been reduced. We present a case of hepatic arterial variation in which Common Hepatic Artery $(\mathrm{CHA})$ originates
\end{abstract}

from not Celiac Trunk but from Superior Mesenteric Artery (SMA) which is established in preoperative MDCT Angiography of a patient scheduled for Whipple operation for cancer of pancreatic head.

Keywords: Preoperative MDCT angiography; Vascular variations; Hepatic arterial variations

\section{Introduction}

The standart surgical procedure for the tumors of pancreatic head, the bile duct close to this area, and duodenum is Whipple operation (pancreaticoduodenectomy). In this operation pancreatic head, entire duodenum, gallbladder, associated bile ducts and part of the stomach are removed. This procedure is exeedingly complex and so it is required to be experienced. A variation in the course of hepatic artery both increases the duration of the procedure and the risk of injury to the hepatic artery which can result in hemorrhage, ischemia and anastomotic leak $[1,2]$. In the anatomical observations made with large series of cases [3-5] various types of hepatic arterial variations were noted in $21-45 \%$ of cases. For this reason, in terms of the surgical success it is very important to establish variations before the operation. We present a case that have one of the rarest hepatic arterial variation in which CHA is directly originated from SMA, established by preoperative MDCT.

\section{Case}

A 56 year old man presented to our hospital with epigastric pain and jaundice. He was evaluated and a tumor was established at uncinnate process of the pancreatic head by abdominal CT imaging. Therefore, he was scheduled for Whipple operation. After that, for staging and to assess the relation of the mass with vascular structures 3 phase MDCT Angiography was performed. 64 channel MDCT (Philips Brilliance 64) with $1 \mathrm{~mm}$ section thickness and $0.5 \mathrm{~mm}$ reconstruction interval was used and $120 \mathrm{kVp}$ and $300 \mathrm{~mA}$ were chosen. Non-ionic contrast agent (omnipaque $350 \mathrm{mg} / 50 \mathrm{ml}$, GE Healthcare Canada) was infused at $5 \mathrm{ml} / \mathrm{min}$ and the region was imaged at arterial, portal and venous phases by using bolus tracking method. By reconstruction sagittal and coronal images were obtained from axial images. 3 dimensional images were made with MPR, MIP and VR methods. It was seen that celiac trunk was giving LGA and SA but not the CHA which was originating directly from SMA (Figure 1). Its course then was superior to the head of the pancreas (Figure 2). With the help of our radiology department intraoperative localization of CHA was made successfully. As a result with the knowledge of this variant anatomy assessed in MDCT Angiography our patient had a safe operation.

\section{Discussion}

In the classic anatomy, the common hepatic artery (CHA) originates from celiac trunk with left gastric artery and splenic artery. CHA then gives rise to gastro duodenal artery, proper hepatic artery which divides into right and left hepatic arteries. In order to describe the variations the terms accessory and replaced are used. Both of these terms can be referred as aberrant. Accessory vessel is one that supplies a part of the viscera in addition to its normal vascular supply but a replaced vessel originates from an atypical location and provides entire blood supply to this part of the viscera [6]. Existence of an aberrant hepatic arterial anatomy makes more difficult the procedure and increases the risk of complications [7]. Therefore, preoperative awareness of hepatic arterial variations is important for effective surgical and radiologic procedures and helps to avoid iatrogenic complications. DSA is the gold standart imaging modality for vascular structures but its invasive nature limits its use. With the use of MDCT Angiography vascular structures can be scanned in just one breath hold without any artifacts. Axial and three dimentional images give detailed information regarding vasculature.

In 1960s with a study on 200 cadavers Michels et al. made the first description including 10 types of variations classifying accessory and replaced hepatic arterial systems separately [3]. After that, in 1994 this classification was simplified to 6 types by Hiatt et al. after their study on 1000 donors liver for orthotopic liver transplantation [4]. The differentiation between accessory and replaced hepatic arterial system was not made in this revised form of the classification. In our case CHA originated directly from SMA (hepatomesenteric trunk), while LGA and SA are originating from celiac trunk. This variation is classified as type 9 in Michell classification with the frequency of $2.5 \%$ and type 5 in Hiatt classification with the frequency of $1.5 \%$. Rammohan et al. [7] searched hepatic arterial anomalies in 225 patients who experienced pancreaticoduodenectomy while Perwaiz et al. $[8,9]$ searched that in 200 patients and they saw only one case in each search that CHA was

*Corresponding author: Ebru Yılmaz, MD, Department of Physical Medicine and Rehabilitation ,GOP Taksim Education and Training Hospital, Istanbul, Turkey, E-mail: ebruyilmaz99@yahoo.com

Received December 17, 2015; Accepted February 05, 2016; Published February 13, 2016

Citation: Atca AO, Yılmaz E, Erok B, Yılmaz A, Eyupoglu E, et al. (2016) A Rare Hepatic Arterial Variation Established in Preoperative MDCT Angiography. Surgery Curr Res 6: 260. doi:10.4172/2161-1076.1000260

Copyright: @ 2016 Atca AO, et al. This is an open-access article distributed under the terms of the Creative Commons Attribution License, which permits unrestricted use, distribution, and reproduction in any medium, provided the original author and source are credited. 
Citation: Atca AO, Yılmaz E, Erok B, Yılmaz A, Eyupoglu E, et al. (2016) A Rare Hepatic Arterial Variation Established in Preoperative MDCT Angiography. Surgery Curr Res 6: 260. doi:10.4172/2161-1076.1000260

Page 2 of 2

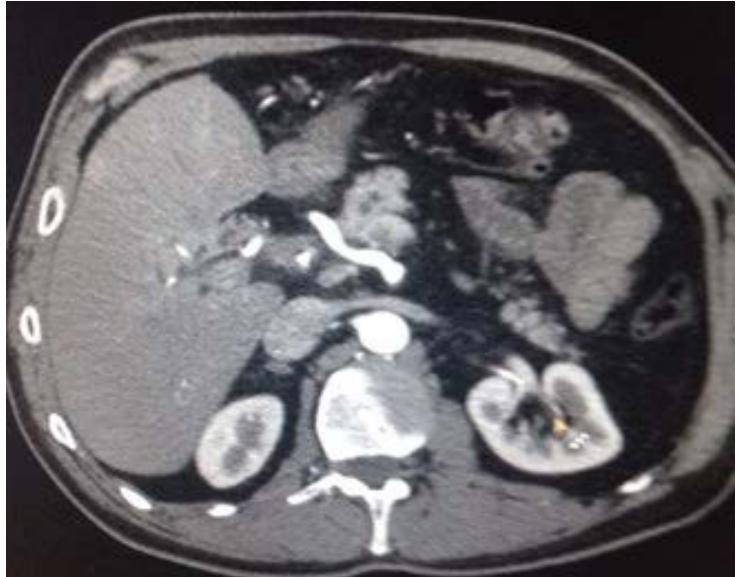

Figure 1: 3D MDCT Angiography showing the $\mathrm{CHA}$ originating directly from SMA instead of Celiac Trunk.

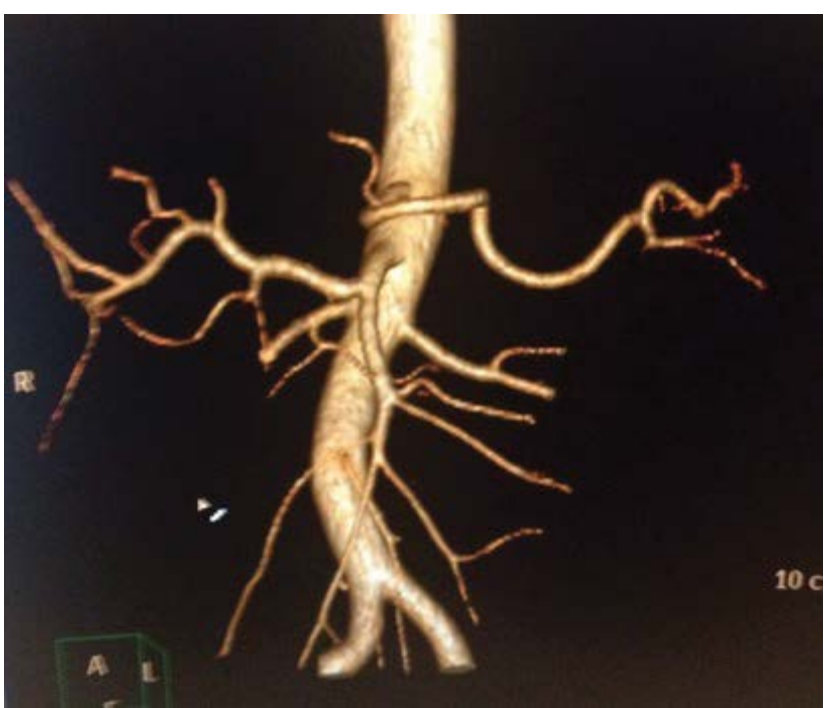

Figure 2: Axial MDCT scan showing CHA originating from SMA coursing posterior to the head of pancreas.

originating directly from SMA. In these studies the frequency of the variation was reported as $2.3 \%$ and $0.5 \%$. In the study made by Song et al. eliac trunk and hepatic artery variations were searched in 5002 patients and in 132 patients (2.64\%) hepatomesenterik trunk and gastrosplenik trunk were established together. In this study also the course of CHA were classified according to pancreas (supra-trans and infra), portal vein (preportal-retroportal) and superior mesenteric vein (preSMV-postSMV)) [8]. In our case, the course of CHA was suprapancreatic and retro portal. When we look at the variations of hepatic artery as a whole we see that hepatomesenteric trunk variations are one of the rarest one $[3,4,7,9,10]$. In addition, not recognizing this variation during the operation can result in the ligation of CHA and necrosis of the liver [11].

In conclusion, MDCT is a non-invasive and quick imaging modality that makes 3 dimensional evaluation possible in the preoperative establishment of vascular anomalies. Before complex operations like transplantation and whipple operation to minimize the possible complications existence of vascular variations must be searched by MDCT.

\section{References}

1. Shukla PJ, Barreto SG, Kulkarni A, Nagarajan G, Fingerhut A (2010) Vascular anomalies encountered during pancreatoduodenectomy: do they influence outcomes?. Ann Surg Oncol 17: 186-193.

2. Chamberlain RS, El-Sedfy A, Rajkumar D (2011) Aberrant hepatic arteria anatomy and the whipple procedure: lessons learned. Am Surg. 77: 517- 526.

3. Michels NA (1966) Newer anatomy of the liver and its variant blood supply and collateral circulation. Am J Surg 112: 337- 347.

4. Hiatt JR, Gabbay J, Busuttil RW (1994) Surgical anatomy of the hepatic arteries in 1000 cases. Ann Surg 220: 50-52.

5. Covey AM, Brody LA, Maluccio MA, Getrajdman GI, Brown KT (2002) Variant hepatic arterial anatomy revisited: digital subtraction angiography performed in 600 patients. Radiology 224: 542-547.

6. Standring S (2005) Gray's Anatomy. The Anatomical Basis of Clinical Practice, 40th ed. Philadelphia; Elsevier Churchill, Livingstone. 3460.

7. Rammohan A, Palaniappan R, Pitchaimuthu A, Rajendran K, Perumal SK, et al (2014) Implications of the presence of an aberrant right hepatic artery in patients undergoing pancreaticoduodenectomy. World journal of gastrointestinal surgery 6: 9-13.

8. Song SY, Chung JW, Yin YH, Jae HJ, Kim HC, et al. (2010) Celiac axis and common hepatic artery variations in 5002 patients. Systematic analysis with spiral CT and DSA. Radiology 255: 278-288.

9. Perwaiz A, Singh A, Singh T, Chaudhary A ( 2010) Incidence and management of arterial anomalies in patients undergoing pancreaticoduodenectomy. JOP 11: $25-30$.

10. Rubio-Manzanares DM, Marín-Gómez LM, AparicioSD, Suárez AG, Bellido C et al. (2015) Implication of the presence of a variant hepatic artery during the Whipple procedure. Rev Esp Enferm Dig 107: 417-422.

11. Kayaalp C, Nessar G, Kaman S, Akoglu M (2001) Right liver necrosis: complication of laparoscopic cholecystectomy. Hepatogastroenterology 48 1727-1729. 